\title{
Immigration, human capital and growth in the host country
}

\section{Evidence from pooled country data}

\author{
Juan Dolado ${ }^{1}$, Alessandra Goria ${ }^{2}$, and Andrea Ichino ${ }^{3}$ \\ 'Bank of Spain and CEPR \\ ${ }^{2}$ Fondazione Eni Enrico Mattei \\ ${ }^{3}$ Fondazione Eni Enrico Mattei and IGIER
}

\begin{abstract}
Immigration, as a source of population growth, is traditionally associated, by neoclassical economics, with negative output and growth effects for the host economy in per capita terms. This paper explores how different these effects can be when the human capital brought in by immigrants upon arrival is explicitly considered in a Solow growth model augmented by human capital and migration. The main finding is that the negative output and growth effects of immigration tend to become less important the higher the imported immigrants' human capital relative to natives. In order to evaluate the order of magnitude of these effects, descriptive evidence, based on education data, and econometric evidence, based upon the estimation of the transition equation in the augmented Solow model, is provided for a set of OECD economies during the period 1960-1985. Because of their human capital content, migration inflows are shown to have less than half the negative impact of comparable natural population increases.
\end{abstract}

\section{Introduction}

Population growth is traditionally associated, by neo-classical theory, with negative effects in per capita terms on output and growth, the reason being the undisputed assumption of decreasing returns to labour in the production function. Immigration, as a source of population growth, has therefore understandably shared the same presumption of negative per capita effects. However, immigrants are not like new-born babies: when they enter the host country they bring with themselves the human capital accumulated in the country of origin and

We would like to thank H. Zlotnick at the UN for providing a crucial part of the dataset, O. Bover. G. Luciani, A. Worgotter, three referees and Seminar participants at the Bank of Spain, the Fondazione Mattei and IGIER for their advice. Particularly helpful comments and suggestions came from X. Sala-i-Martin, to whom we feel very much indebted. A. Ricardo provided expert research assistance. Financing from the Fondazione Eni Enrico Mattei for Alessandra Goria and for Andrea Ichino is gratefully acknowledged. 
after arrival they contribute to the human capital accumulation in the host economy in a way which may be different from that of native new-borns.

The traditional production function in which output is produced with physical capital and labour does not leave too much room for a positive immigrants' contribution to output and growth via the human capital they bring in with themselves or via their capacity to accumulate skills in the host economy. Yet the most recent growth literature has highlighted the importance of considering explicitly human capital as one of the reproducible factors of production. For the "endogenous growth" literature, the introduction of human capital in the production function has represented one way to justify the existence of constant returns to the reproducible factor, thereby allowing for a steady state constant growth without convergence. ${ }^{1}$ More recently, Mankiw, Romer and Weil (1992) (MRW hereafter) have shown that, without the assumption of a constant return to the reproducible factor, "an augmented Solow model that includes accumulation of human as well as physical capital provides an excellent description of cross-country data", and that "holding population growth and capital accumulation constant, countries converge at about the rate the augmented Solow model predicts."

These recent developments of the growth literature invite an explicit consideration of the human capital contributions of immigrants to the host economy. As already anticipated above, there are two ways in which immigrants can contribute to the human capital accumulation in the receiving country: first, they bring with themselves the skills they have acquired before arrival, and, second, after arrival, they accumulate human capital differently than natives or they can influence the natives accumulation of knowledge.

Starting with this second effect the migration literature has seen in the "assimilation process" a major mechanism driving the immigrants' accumulation of human capital after arrival. ${ }^{2}$ More recently, however, the fact that a significant favourable assimilation process should always accompany any migration inflow has been disputed. ${ }^{3}$ Independently from the position taken in this debate, inasmuch as immigrants accumulate human capital differently than natives, the assimilation (or "dissimilation") process has at least the potential for being an important factor for the host economy growth. In addition, as for example recently suggested by Cartiglia (1992), immigrants may also indirectly influence the natives' accumulation process, beyond their direct capacity to contribute to the stock of reproducible factors.

Despite the likely importance of the immigrants' propensity to accumulate human capital or of their capacity to influence the native accumulation, in this paper we will not focus on these types of effects, mostly because it is difficult to find a framework in which to consider the issue in a way suitable of empirical verification. $^{4}$

1 See Lucas (1988), Rebelo (1991) and the extremely clear and useful survey of endogenous growth models contained in Sala-i-Martin (1990).

2 See, for example, Chiswick (1979 and 1980).

3 See, for example, Borjas (1985, 1987, 1990) and Benjamin and Baker (1990).

4 The literature already offers models in which the immigrants' accumulation of human capital can be (and has been) explored with individual data [see works by Chiswick (1979-1980) and Borjas (1985-1990), the surveys by Greenwood and McDowell (1986) and Ichino (1993)]; it also offers aggregate growth models that stress the importance of human capital accumulation for growth and tests it with aggregate data [see, for example, the literature already quoted in footnote 1 and Mankiw et al. (1992)]. The problem, in our opinion, is to bridge theoretically and, in particular, empirically the two types of models. 
Here, instead, we focus on the other type of immigrants' contribution to the host country human capital mentioned above: i.e. the stock of already accumulated skills that immigrants bring with themselves when they enter the country. The issuc is obviously not new in the literature ${ }^{5}$, but the implications for output and growth in the host economy have been relatively less explored. Burda and Wyplosz $(1991 \mathrm{a}, \mathrm{b})$ have recently openly addressed this issue in order to evaluate, at a theoretical level, the output and growth effects of migration from eastern to western Europe. Being likely that the composition of migrants will tend to reflect more highly educated workers, their analysis suggests the possibility of "deleterious effects on the economies left behind" while even "receiving countries may ... suffer negative effects, at least in the short run". More generally, they conclude that "the impact of several million future migrants on the economic development of western Europe should bring new evidence to bear on the role of external human capital in the production function."

As a contribution to prepare ourselves to that impact, in this paper we explore the dimension and the role of the human capital brought in by immigrants for the output level and the growth rate of the receiving economies. Section I provides descriptive evidence, based on education data, on the human capital content of international migration flows for nine major receiving countries for which we could get quality data on immigration sources and suggests that such human capital content may indeed be fairly high and similar to the native one. To provide a framework for the econometric analysis, Sect. II analyses the implication of these findings within a Solow growth model augmented by human capital and migration, in which the negative output and growth effects of immigration are shown to become less important the higher the immigrants' human capital. However, the human capital of immigrants has to be much higher than that of natives in order to eliminate the negative impact of migration inflows. In Sect. III, the conclusions of the theoretical section are shown to be supported by an econometric analysis based on a pooled country dataset consisting of 23 OECD economies for the period 1960-1985. Using the estimated model, the size of the output and growth effects of immigration are then measured. Furthermore, econometric estimates of the human capital content of migration inflows relative to natives are shown to be in line with the descriptive evidence based on the education data presented in Sect. I. Concluding remarks follow.

\section{Descriptive evidence on the human capital content of migration flows}

Before exploring the output and growth effects of immigration when human capital is taken into account, we want to provide some descriptive evidence on the skills content of migration flows. Given the well known lack of good data on international migration, the scope of this section is necessarily limited. No evidence

\footnotetext{
5 See Chiswick (1978), Borjas (1990), Greenwood and McDowell (1986), Simon (1989) and Stark (1991) and in particular R. Blitz (1977) and the pioneering study by C. Gini (1940), that attempt to evaluate quantitatively the human capital brought in by immigrants in a cost-benefit analysis framework.
} 
based on individual data will be provided, but just some measures of the human capital of immigrants based on aggregate information. ${ }^{6}$

The methodology that we have followed is based on figures on the number of immigrants by country of origin and on education data. The number of immigrants by country of origin was obtained, from a United Nation source ${ }^{7}$, for the following nine major receiving countries: Australia, Belgium, Canada, Germany, Netherlands, Sweden, Switzerland, United Kingdom, and United States. For most of these countries the time series covered the 1960-1987 period, but for some of them the period was significantly shorter. ${ }^{8}$

Table 1 provides some evidence on the size of these migration inflows in comparison with population growth. On average, immigrants appear to be a very important source of population growth for these countries. This is even more true in the $70 \mathrm{~s}$ and $80 \mathrm{~s}$, in which the effects of the "baby boom" appear to be over. If on average, the population growth due to immigrants was $56 \%$ of the total population growth in the $60 \mathrm{~s}$, this percentage becomes $91 \%$ in the $70 \mathrm{~s}$ and it climbs up to $111 \%$ in the 80 s. $^{9}$

Having established that immigration may represent a significant source of population growth, it it important to notice that there is a substantial difference between the growth due to immigrants and the growth due to new-borns: immigrants, as opposed to babies, enter the host country with some (possibly large) human capital. Hence, measuring the human capital contribution of immigrants is important in order to understand if the two sources of total population growth may have different output and growth effects.

Table 1. Population growth and immigration rate

\begin{tabular}{|c|c|c|c|c|c|c|}
\hline \multirow[t]{2}{*}{ Host countries } & \multicolumn{3}{|c|}{$\%$ Population growth } & \multicolumn{3}{|c|}{$\%$ Immigration rate } \\
\hline & $60 / 69$ & $70 / 79$ & $80 / 87$ & $60 / 69$ & $70 / 79$ & $80 / 87$ \\
\hline Australia & 1.99 & 1.70 & 1.42 & 1.22 & 0.73 & 0.67 \\
\hline Belgium & 0.59 & 0.23 & 0.03 & 0.75 & 0.63 & 0.49 \\
\hline Canada & 1.80 & 1.22 & 1.07 & 0.72 & 0.65 & 0.46 \\
\hline Germany & 0.90 & 0.21 & -0.04 & 1.12 & 1.14 & 0.85 \\
\hline The Netherlands & 1.28 & 0.87 & 0.54 & 0.55 & 0.69 & 0.58 \\
\hline Sweden & 0.70 & 0.40 & 0.09 & 0.50 & 0.52 & 0.43 \\
\hline Switzerland & 1.51 & 0.36 & 0.35 & & 0.81 & 1.05 \\
\hline United Kingdom & 0.58 & 0.16 & 0.14 & 0.37 & 0.35 & 0.36 \\
\hline United States & 1.29 & 1.05 & 1.00 & 0.17 & 0.20 & 0.25 \\
\hline Countries' average & 1.18 & 0.69 & 0.51 & 0.67 & 0.64 & 0.57 \\
\hline Standard dev. of logs & 0.47 & 0.86 & 1.31 & 0.62 & 0.51 & 0.44 \\
\hline
\end{tabular}

6 These measures represent an admittedly imperfect estimate of the actual economic variables that we would like to document. Nevertheless they are the most informative measures we could construct with the available data and we hope that, despite their many weaknesses, something can be learned from them.

See Zlotnick (1990) and Zlotnick and Hovy (1990).

8 The reader should also keep in mind that these are official figures on legal entries in the receiving country and that not for all countries the list of origins is very detailed: for example, we go from almost 220 countries of origin for the case of Canada to 5 for Switzerland. More information on the characteristics of these immigration data is provided in Zlotnick and Hovy (1990).

9 Obviously this percentage may exceed $100 \%$ because of emigrants out of the host economy. 
In the absence of more detailed information, in order to ascertain the human capital content of migration flows we have looked for yearly measures of schooling in the countries from which these flows were originated. We found three sources of relevant information on education: first, the data on secondary school enrolment from the World Bank; second, the series of school attainment constructed by Kyriacou (1991) and third, the series of school attainment constructed by Barro and Lee (1992), both representing the average number of completed years of schooling ${ }^{10}$. Notice that the first measure can be thought as an indicator of investment in human capital, while the two latter are to be considered as stock measures.

Defining:

$$
h_{i t}=\text { schooling measure for the country } i \text {, in period } t \text {, and }
$$

$M_{j i t}=$ number of immigrants in the host country $j$, from the origin $i$, in period $t$, for each host country and for each schooling measure, we have constructed the following two indicators:

$$
\begin{aligned}
& H_{j t}=\frac{\sum_{i} h_{i t} M_{j i t}}{\sum_{i} M_{j i t}} \\
& \varepsilon_{j t}=\frac{H_{j t}}{h_{j t}}
\end{aligned}
$$

average human capital of the immigrants going to country $j$ in period $t$

ratio of the human capital of immigrants versus natives in country $j$ and in period $t$.

These indicators are based on the hypothesis that immigrants are randomly chosen from the original population. This hypothesis can clearly be disputed along the lines of the debate on how immigrants are selected from the population in the country of origin. The traditional view in the migration literature ${ }^{11}$ holds that immigrants are likely to be the most skilled in the country of origin while more recently it has been argued that the least skilled may be those who emigrate from the sending country if, for example, the income distribution is more compressed in the host country than in the sending one ${ }^{12}$. In the light of these different possibilities, we believe that a human capital measure like the one constructed in this paper may represent a satisfactory first order approximation to the real variable we would like to document. Indeed, there are good theoretical reasons to think that our measures could represent either a lower or an upper bound for the true measure.

Unfortunately, our immigrants' human capital indexes suffer from other weaknesses. For example, it can be argued that schooling indicators do not fully measure the whole human capital that is relevant for the production function and, indeed, on-the-job-training or apprenticeship accumulated in the sending country are totally disregarded by our measures. We do not see any feasible way to over-

\footnotetext{
10 For a detailed description of the methodology followed to construct the series see the original papers (Kyriacou 1991 and Barro-Lee 1992).

11 See, for example, Chiswick $(1979,1980)$.

12 See Borjas $(1985,1990)$.
} 
come this problem with the available aggregate information on migration flows. However, in the theoretical section we will point out that what is really relevant from the perspective of growth is the ratio between the human capital of immigrants and that of natives. Under the admittedly restrictive assumption that the immigrants/natives ratio for education indexes is similar to the immigrants/natives ratio for on the job training indexes, the first ratio (i.e. $\varepsilon_{j t}$ ) can be used as an approximation to the overall human capital content of migration inflows relative to natives. To our defence, we can also say that in the empirical growth literature, education has been widely used as a proxy for total human capital. ${ }^{13}$

Another source of problems is the fact that schooling indicators are not likely to be comparable across countries, since education systems differ around the world. And even assuming that schooling were comparable, the immigrants' human capital in a more general sense may not be easily adapted to the characteristics of the host country: after all production technologies differ across countries, and immigrants who are very skilled in their country of origin may find out that their capacities are obsolete in the host country.

Letting aside doubts, not because we think they are irrevelant but just because this is "the only game in town" with the available aggregate data, Fig. 1 summarises what these indexes can tell us. For the three different schooling measures described above, we plot the average human capital ratio of immigrants versus natives across the countries considered in this section (i.e. the average of the $\varepsilon_{j t}$ indicators across host countries). This average ratio is never below 0.7 , reaching in some years the value of 0.9 , and these high values are basically confirmed by each of the three indexes.

In each panel of Fig. 1, we also plot the human capital ratio of immigrants versus natives as if all immigrants were coming from the 90th or 10th percentiles of the human capital distribution across countries. For each index, the actual ratio is closer to the "90th percentile" ratio, implying that migration flows contain a large amount of immigrants coming from countries in the upper end of the international distribution of human capital.

Thus, if we are willing to accord some credibility to these measures, the human capital of immigrants is quite significant, and fairly similar to the human capital of natives. ${ }^{14}$ In the next section we explore at a theoretical level which are the possible effects of migration inflows when such levels of immigrants' human capital are taken into account.

$\overline{13}$ See among others, Barro (1991), Barro and Sala-i-Martin (1991) and MRW.

14 In the working paper version of this article [see Dolado et al. (1993)] we describe other features of these indicators, looking more closely at the individual host countries. In particular, our human capital measures show that the United States attracted the less skilled immigrants in comparison to Canada and Australia. Australia appears to be the country that on average did better in attracting skilled immigrants, while Canada from being close to Australian standards in the 60 s is reached by the United States in the 80s. These results confirm well established previous findings obtained with other data in the migration literature [see, for example, Borjas (1990)]. We consider this correspondence of results as a factor that enhance the reliability of our measures. 


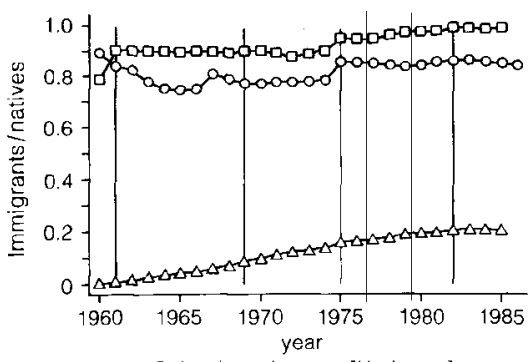

School attainment [Kyriacou]

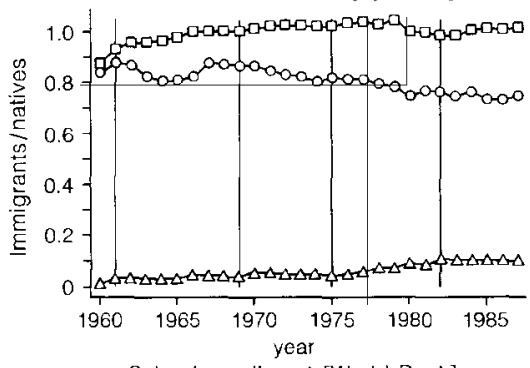

School enrollment [World Bank]

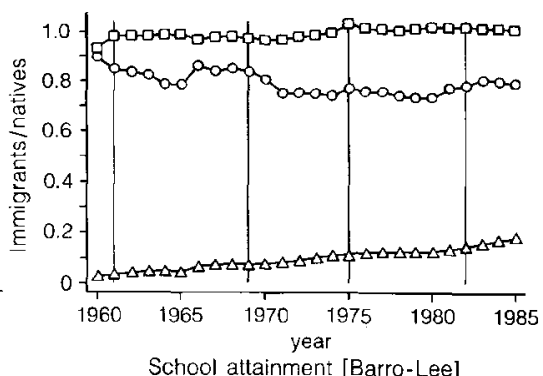

- Immigrants/natives

$\triangle 10$ th percentile/natives

口 90th percentile/natives

Fig. 1. Human capital of immigrants versus natives (avcrages across selected host countries); vertical bars denotc changes in the number of countries on which the average is computed

\section{The theoretical framework}

In this section we set out the basic theoretical framework in which we would like to explore the output and growth effect of immigration. With some modifications, the model is that of Solow (1956) augmented by human capital and by migration. As in the MRW version of the Solow model, we consider an economy in which output is produced with labour, human capital and physical capital. The technology is assumed to be represented by a constant return to scale Cobb Douglas production function such that (omitting time subscripts)

$$
Y=H^{\alpha} K^{\beta}\left(L e^{g t}\right)^{1-\alpha-\beta} \mid \quad 0<\alpha, \beta<1,
$$

where $Y$ is the output level, $H$ is human capital, $K$ is physical capital and $L$ is the total working population (natives plus new net immigrants) whose productivity grows at an exogenous rate $g$. Here and in the rest of this paper, natives include immigrants arrived in previous periods. Thus, the working population growth rate is given by

$$
\frac{\dot{L}}{L}=n+\frac{M}{L}=n+m,
$$

where $n$ is the growth rate of the native population, $M$ is the (net) number of new immigrants and therefore $m=M / L$ is the net immigration rate. The number of effective units of labour grows not only because of population growth but also because of the labour augmenting technological growth rate $g$. 
Human capital accumulation has three sources: first, a fixed proportion of total output is devoted to increase the stock of $H$; second, depreciation reduces the existing stock; and, third, new immigrants bring with themselves their own human capital that is added in each period to the human capital of the host country. Therefore, the human capital accumulation equation is given by

$$
\dot{H}=s_{h} Y-\delta H+M \varepsilon_{h} \frac{H}{L}=s_{h} Y-\delta H+m \varepsilon_{h} H,
$$

where $s_{h}$ is the fraction of output that is invested, $\delta$ is the depreciation rate and $\varepsilon_{h}$ is the fraction of the existing stock of host country per capita human capital that is brought in by each new immigrant. In other words $\varepsilon_{h} H / L$ is the human capital that each new immigrant adds to the host country stock when she/he enters the country. Notice that the right hand side of (3), without $m \varepsilon_{h} H$, corresponds to the standard accumulation equation in the human-capital-augmented Solow's model without migration (see MRW).

Physical capital accumulation has instead only the two traditional sources: first, a fixed proportion of total output is devoted to increase the stock of $K$; second, depreciation reduces the existing stock. Therefore, the physical capital accumulation equation is given by

$$
\dot{K}=s_{k} Y-\delta K
$$

where $s_{k}$ is the fraction of output that is invested and $\delta$ is the depreciation rate ${ }^{15}$.

Letting small cases denote variables per effective unit of labour, Eq. (1), (3) and (4) can be rewritten as:

$$
\begin{aligned}
& y=h^{\alpha} k^{\beta} ; \quad y=\frac{Y}{L e^{g t}}, \quad h=\frac{H}{L e^{g t}}, \quad k=\frac{K}{L e^{g t}} ; \\
& \dot{h}=s_{h} y-\left[\delta+g+n+m\left(1-\varepsilon_{h}\right)\right] h=s_{h} h^{\alpha} k^{\beta}-\left[D+m\left(1-\varepsilon_{h}\right)\right] h, \\
& \dot{h}=s_{k} y-[\delta+g+n+m] k=s_{k} h^{\alpha} k^{\beta}-[D+m] k,
\end{aligned}
$$

where $D$ is the standard capital requirement defined by $D=n+\delta+g$.

15 As in MRW, we assume, for simplicity, an identical depreciation rate for the two types of capital.

Comparing (3) and (4), notice that immigrants are assumed to contribute only to human capital $\left(\varepsilon_{h}\right)$. Although, in principle, this seems reasonable, there might also be good reasons to justify a positive contribution of immigrants to physical capital $\left(\varepsilon_{k}\right)$. For example an inflow of immigrants may prevent the dismantling of some obsolete physical capital, or, in the presence of spared capacity, immigrants may allow for an increase of the stock of physical capital effectively used in production. However, the impossibility to identify both thesc immigrants' factor contributions in our econometric framework, forces us to omit one of them from our theoretical framework. Since the human capital contribution is presumably the most relevant of the two direct effects of immigration on the accumulation of reproducible factors, $\varepsilon_{h}$ will be the focal point in this paper, and therefore $\varepsilon_{\mathrm{k}}$ is excluded from (4). 
Within this framework, abstracting from the possibility of capital mobility, the marginal returns of human and physical capital should be equated (in the absence of adjustment or irreversibility costs); therefore ${ }^{16}$ :

$$
\frac{\partial y}{\partial h}=\frac{\partial y}{\partial k} \Rightarrow \frac{h}{k}=\frac{\alpha}{\beta} \text {. }
$$

Under these assumptions it is possible to aggregate the two types of capital into one composite reproducible factor $C$ such that

$$
C=k+h
$$

and

$$
y=\Phi C^{\alpha+\beta} \quad \text { where } \quad \Phi=\left(\frac{\alpha}{\alpha+\beta}\right)^{\alpha}\left(\frac{\beta}{\alpha+\beta}\right)^{\beta} .
$$

Since $h=\frac{\alpha}{\alpha+\beta} C$ and $k=\frac{\beta}{\alpha+\beta} C$, the accumulation equation for the composite reproducible factor $C$ is easily obtained, from (6) and (7):

$$
\dot{C}=\dot{h}+\dot{k}=s \Phi C^{\eta}-[D+m(1-\varepsilon)] C,
$$

where $s=s_{h}+s_{k}$ is the combined propensity to invest, $\eta=(\alpha+\beta)$ is the joint return to the composite capital $C$ and $\varepsilon=\varepsilon_{h} \frac{\alpha}{\alpha+\beta}$ is the immigrants' contribution to the accumulation of reproducible factors. ${ }^{17}$ The parameter $\varepsilon$ will be crucial in what follows, because upon this parameter hinge the size and the sign

16 Although the assumption of no capital mobility is extreme, the analysis sheds light on the way in which imperfect capital mobility interacts with the effects of gradual migration.

17 Under the condition (8) of equal marginal factor returns, if immigrants contribute only to the human capital stock, a further assumption has to be made in order to justify the exogeneity of the investment rates, as in the standard Solow model. Indeed, the "closed economy" assumption implies that production always move along the desired ratio $\frac{h}{k}=\frac{a}{\beta}$. This implies $\gamma_{h}=\frac{\dot{h}}{h}=\frac{\dot{k}}{k}=\gamma_{k}$ and, using (6) and (7), this condition can be shown to be equivalent to the following relationship between the investment rates:

$$
s_{h}=s_{k}\left(\frac{\alpha}{\beta}\right)-\varepsilon m\left(\frac{\alpha}{\beta}\right)^{\beta} h^{1-\alpha-\beta} .
$$

Thus, unless $m$ [which is a function of $C$, as it will be assumed below in (12)] exactly offsets $h^{1-\alpha-\beta}$ (and there is no reason to believe that it should), the model does not admit the assumption of two saving rates both contemporaneously constant and exogenous. However, it does allow to assume that the sum of the two investment rates is constant: this occurs if, as $h$ increases because of migration, also the natives accumulation of physical capital $s_{k}$ increases in order to maintain the $h / k$ ratio constant. In this case, also the aggregate saving (investment) propensity $\left(s_{h}+s_{k}\right)$ remains unaltered and this is the assumption behind (11). We are grateful to Xavier Sala-i-Martin for pointing out this issue and for making it clear to us.

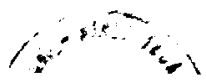


of the output and growth effects of migration. We will refer to it as to the "weighted immigrants' human capital" or to "the aggregate immigrants" capital" relative to natives. At present, notice that, given the evidence presented in Sect. I, $\varepsilon_{h}$, and therefore $\varepsilon$, are likely to be smaller than unity. This implies that the aggregate capital of which each immigrant is endowed is smaller than the per capita aggregate capital of natives. ${ }^{18}$

Finally, the description of the basic structure of the model is concluded by the following stylised migration cquation:

$$
m=\varphi \ln (y)+Z=\varphi \eta \ln (C)+Z+\ln (\Phi),
$$

where $m \geqslant 0$ if $C \geqslant C_{m}$ and $C_{m}$ is the level of aggregate capital at which net migration is zero. According to this equation the (net) migration rate depends on the log of per capita income in the host country and on a set of exogenous variables $Z$ that describe income per capita in the sending countries, the costs of migration and other exogenous characteristics of the host and sending countries that may influence the migration flow, but are not immediately relevant for the present analysis. We will refer to this variable as to exogenous net migration. ${ }^{19}$

The dynamic behaviour of this economy can be described with the help of Fig. 2 which plots (for the more realistic case in which $\varepsilon<1$ ) the two terms on the right hand side of the following equation, in which, using (11) and (12), the growth rate $\gamma$ of the composite capital in the host economy is defined:

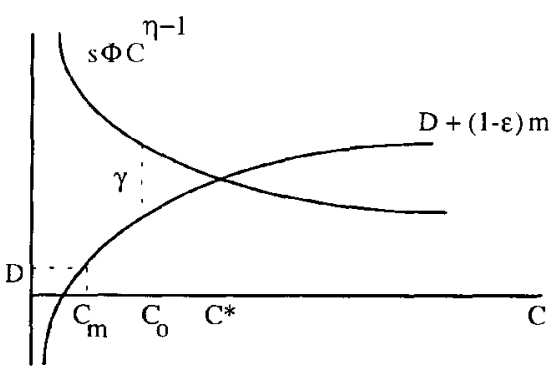

Fig. 2. The growth rate and the steady state (if immigrants have less aggregate capital than natives)

18 Notice that if immigrants contribute to the accumulation of physical capital (see footnote 16), $\varepsilon$ in (11) would be given by

$$
\varepsilon=\frac{\alpha \varepsilon_{h}+\beta \varepsilon_{k}}{\alpha+\beta} .
$$

In this case the immigrants' contribution to the composite reproducible factor would be a weighted average of $\varepsilon_{h}$ and $\varepsilon_{k}$ with the weights being given by the output shares of human and physical capital. 19 This parsimonious specification of the migration equation is justified by the fact that the focus of this paper is not on the migration decision. We just want to highlight the endogeneity of the migration flow with respect to the output level in the receiving country on which our study is focused.

Notice that total net migration can in principle be positive or negative depending on $C$ being larger or smaller than $C_{m}$. However, in this paper, we will be mainly focused on receiving countries, in which $m>0$. 


$$
\gamma=\frac{\dot{C}}{C}=s \Phi C^{\eta-1}-[D+(\varphi \eta \ln (C)+Z)(1-\varepsilon)]
$$

The vertical distance between the two lines, in Fig. 2, measures the current growth rate, while the steady state is defined by the point in which the two lines cross. $C_{0}$ denotes the current level of aggregate capital and $C_{m}$ is the level of aggregate capital at which net migration is zero. Given the way we drew the curves so that $C^{*}>C_{m}$, the host economy is a recipient of migrants in steady state $\left(m^{*}>0\right)$.

Moving to the main focus of this paper, we will explore, using this framework, the effects of immigration on the current growth rate, on the steady state towards which the host country is moving and on the speed of adjustment to such steady state. $^{20}$

\section{II.1 The current growth rate and the steady state}

The effects of a higher (weighted) immigrants' human capital, for a given size of the migration flow, are described in Fig. 3 by a downward shift in the $D+m(1-\varepsilon)$ curve (assuming $m>0$ ):

If the host economy is a net receiver of immigrants $(m>0)$ a higher (weighted) immigrants' human capital has undoubtedly a positive effect on both the steady state and the current growth rate of the host economy $\left(C^{*}>C^{*}\right.$ and $\left.\gamma^{\prime}>\gamma\right)$. On theoretical grounds, it is almost obvious to expect such result. Similarly reasonable is the other face of the story: an increase of the human capital of net migrants out of a sending country decreases its growth rate. Maybe less obvious is one important consequence of these results: i.e. an increase in the human capital content of migration flows appears to be a factor that reduces the capacity of migration to induce convergence of per capita output level across countries $[\sigma-$ convergence in the terminology of Barro and Sala-i-Martin (1991)]. In other words, the brain drain from poor countries to rich countries may play an impor-

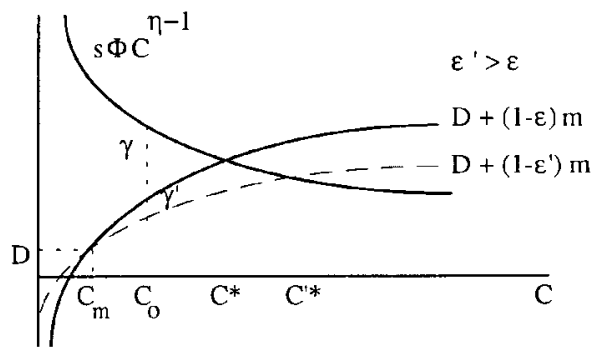

Fig. 3. Effects of a higher immigrants' human capital (if immigrants have less aggregate capital than natives)

20 The comparative static results concerning the propensity to invest $s$ and the variables included in $D$ are, in this economy, qualitatively similar to the ones that can be obtained from the basic Solow model without migration. 


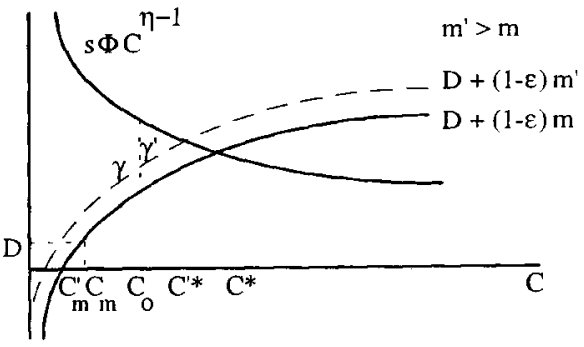

Fig. 4. Effects of a higher net immigration rate (if immigrants have less aggregate capital than natives)

tant role in explaining the slow convergence to similar standard of living across countries despite the size of international migration flows. ${ }^{21}$

Holding constant the average human capital of immigrants, the consequences of a larger migration inflow are described in Fig. 4 by an upward shift of the $D+m(1-\varepsilon)$ curve. If the size of the migration inflow increases, for a given level of the (weighted) immigrants' human capital, and if immigrants have less aggregate capital than natives, the host economy will suffer a lower steady state output per capita and a lower growth rate during the adjustment to the steady state. The sign of the effects are reversed if immigrants have more aggregate capital than natives.

Notice that if $\varepsilon=1$, exogenous increases of the net migration rate would have no effect on the steady state and on the growth rate. Under the more likely hypothesis of $\varepsilon<1$, this model suggests that, holding constant the current per capita output levels, larger migration flows from poor to rich countries should decrease the current growth rate of the rich ones and increase the current growth rate of the poor ones. Therefore larger migration flows should cause a decline of the cross-sectional dispersion of per capita income. Nevertheless, as already mentioned, the higher the immigrants' human capital, the lower the capacity of migration flows to induce convergence across countries. ${ }^{22}$

\section{II.2 The speed of conditional convergence}

If instead of holding constant the initial conditions we hold constant the steady state it is possible to define a second concept of convergence, known in the literature as "conditional convergence". ${ }^{23}$ Approximating around the steady state, the growth rate of per capita output in the host economy can be written as

\footnotetext{
21 The reader should keep in mind, however, that such speculations on convergence are based on a one country model in which the human capital content of immigrants relative to natives has been assumed constant and exogenous. To derive conclusions on the effects of the immigrants' human capital on convergence one would need a more sophisticated analysis based on a two countries model in which $\varepsilon$ were considered as an endogenous variable. Working on such a model comes next in our research agenda.

22 See, however, the previous footnote for some caveats concerning these speculations on the process of convergence across countries.

23 See Barro and Sala-i-Martin (1991), Mankiw, Romer and Weil (1992) and Cohen (1992). Barro and Sala-i-Martin refers to this concept also with term " $\beta$-convergence", where $\beta$ is the speed of convergence ( $\lambda$ in our notation).
} 


$$
\frac{\dot{y}}{y}=\ln (\dot{y})=\lambda\left[\ln \left(y^{*}\right)-\ln \left(y_{0}\right)\right]
$$

where

$$
\lambda=(1-\eta)\left[\left(D+m^{*}\right)(1-\varepsilon)\right]+\varphi \eta(1-\varepsilon) \cdot{ }^{24}
$$

In other words the current growth rate can be written as a fraction, $\lambda$, of the percentage distance between the steady state and the current output level. Therefore, $\lambda$ measures the convergence rate to the steady state, i.e. the speed at which the distance to the steady state is covered.

From Eq. (15) it is possible to infer how the speed of adjustment is influenced by the human capital content and by the size of the migration inflow. If the (weighted) human capital content of the migration inflow increases, for a given size of the inflow, the speed of adjustment to the steady state will decrease in the host economy. On the other hand, if the size of the migration inflow increases, for a given level of the (weighted) immigrants' human capital, and if immigrants have less aggregate capital than natives, the speed of adjustment to the steady state will increase in the host economy. The sign of this second effect is reversed if immigrants have more aggregate capital than natives.

\section{II.3 A summary of the output and growth effects of immigration}

In Table 2 we provide a qualitative summary of the theoretical results obtained so far. The basic message of the table can be stated as follows: ceteris paribus, a larger size of the migration inflow has negative effects on output and growth, while a higher human capital content of the migration inflow has positive effects.

In addition, migration has a positive effect on the speed of convergence, while the human capital endowment of immigrants has the opposite effect. In the econometric section we will complement the qualitative entries of this table with some quantitative estimates of the impact of immigration, but first we need to show how we derive our estimated equations from the theoretical framework described so far.

Table 2. The output and growth effects of immigration of immigrants have less human capital than natives

\begin{tabular}{lcccc}
\hline & \multicolumn{2}{l}{ Effects on } & & \\
& growth rate & speed of convergence & steady state output level & current output levcl \\
\hline$\varepsilon$ & + & - & + & + \\
$m$ & - & + & - & - \\
$S$ & + & + & + & $=$ \\
$D$ & - & + & - & $=$ \\
\hline
\end{tabular}

24 This expression can be easily obtained by log-linearisation of (13) around the steady-state composite factor $C^{*}$. Notice that if $m^{*}=\varphi=0$, i.e. there is no migration, this speed of convergence collapses to the Solow case in which $\lambda_{s}=(1-\eta) D$. 


\section{II.4 The econometric framework}

We move from theory to econometrics applying to our migration-augmented model the same methodology followed by MRW. Conditioning on the steady state net migration rate, the steady state level of aggregate capital is defined, using (11), by

$$
C^{*}=\left(\frac{s \Phi}{D+(1-\varepsilon) m^{*}}\right)^{(1 / 1-\eta)}=\left(\frac{s \Phi}{\left(D+m^{*}\right)(1-\mu)}\right)^{(1 / 1-\eta)}
$$

where

$$
\mu=\frac{\varepsilon m^{*}}{D+m^{*}}
$$

Substituting (16) into the production function (10), taking logs and using the approximation $\ln (1-\mu) \cong-\mu$, yields the following equation for income per capita, $\hat{y}=\frac{Y}{L}$ :

$$
\ln \left(\hat{y}_{t}^{*}\right)=a+\frac{\eta}{1-\eta} \ln (s)+\frac{\eta \varepsilon}{1-\eta}\left(\frac{m^{*}}{D+m^{*}}\right)-\frac{\eta}{1-\eta} \ln \left(D+m^{*}\right)
$$

where

$$
a=g t+\frac{\eta}{1-\eta} \ln (\Phi) \text { and } \eta=\alpha+\beta
$$

Thus, the steady state income per capita depends positively on the aggregate saving rate and negatively on the capital requirement $\left(D+m^{*}\right)$, with the theory predicting that the absolute values of the coefficients of both variables should be the same. Moreover, there is an extra positive effect of migration captured by the "pseudo migration" variable $\frac{m^{*}}{D+m^{*}}$, i.e. the ratio of net migration to total population growth. The (identified) coefficient of this variable enables us to infer the size of $\varepsilon$ implied by the data, allowing for comparisons with the education-based evidence described in Sect. I.

Furthermore, the model suggests a natural regression to study the rate of convergence. The approximation for the growth rate of output per capita, $\gamma_{y}$, described by (14) implies that

$$
\gamma_{y}=g t+\ln \left(\hat{y}_{t}^{*}\right)-\ln \left(\hat{y}_{0}\right)=g t+\left(1-e^{-\lambda t}\right)\left[\ln \left(\hat{y}^{*}\right)-\ln \left(\hat{y}_{0}\right)\right]
$$

where the speed of adjustment is still given by (15). Substituting the steady state value $\hat{y}^{*}$ from (17) into (18) we obtain an estimable equation for the growth rate of per capita income, which will be the object of our econometric analysis: 


$$
\begin{aligned}
\ln \left(\hat{y}_{t}^{*}\right)-\ln \left(\hat{y}_{0}\right)= & g t+\left(1-e^{-\lambda t}\right)\left(a+\frac{\eta}{1-\eta} \ln (s)+\frac{\eta \varepsilon}{1-\eta}\left(\frac{m^{*}}{D+m^{*}}\right)\right. \\
& \left.-\frac{\eta}{1-\eta} \ln \left(D+m^{*}\right)-\ln \left(\hat{y}_{0}\right)\right)
\end{aligned}
$$

Notice that (19), beyond offering the same estimation opportunities of (17), has the advantage, over this latter, of explicitly taking into account out-of-steady state dynamics, while allowing, at the same time to identify the parameters of the steady state. Yet, as noticed by MRW, a potential problem in estimating (19) is that if countries have permanent differences in their production function, i.e. different constant terms "a", these would be part of the error term and would be positively correlated with the initial income, biasing its coefficient (and hence the convergence rate) towards zero. We believe, however, that if panel data is available, as in our case, one could exploit the time dimension of the data to allow for fixed country effects somehow capturing the different tastes and technologies which are not totally explained by holding constant the genuine explanatory variables in (17) and (19). Similarly the potential endogeneity of some of those regressors, particularly $m^{*}$, could be more easily taken into account and dealt with accordingly.

\section{Empirical analysis}

\section{III.1 Econometric specification}

In this section the empirical counterpart of the convergence equation (19) is estimated. The main goal is to obtain estimates of the parameters of interest, i.e. $\eta$, $\lambda$ and $\varepsilon$ in order to give some quantitative indication of the output and growth effects of immigration. To achieve this goal, we use a set of $23 \mathrm{OECD}$ countries (listed in Table 5), for which we could find sufficiently long time series of data on migration flows. The sample size for all variables is 1960-1985.

The traditional approach to estimating this sort of growth convergence regressions would be to estimate the model using a single cross-section of averaged data (as, for example, in Baumol (1986), Dowrick and Nguyen (1989), Barro (1991), Barro and Sala-i-Martin (1991) and MRW). However, as Cohen (1992) has argued, the interpretation of (19) as "convergence toward steady state" will only prevail if the right hand side variables in the steady state equation (17) were to stay constant, an assumption of dubious validity, in particular when such variables have trends. Alternatively, a more satisfactory interpretation would be to view the convergence regression as approaching a conditional "pseudo steady state" given by the current value of the regressors. This implies that one could, in fact, construct such regression for each year in the sample, which still would provide a consistent (and ingenious) way to estimate the parameters of interest.

By favouring this weaker interpretation, our estimation approach makes use of the panel structure of the data to exploit the information in all years of the sample. One possible objection to the use of annual data would be that the estimates become more sensitive to the specification of the error term, particularly if it has serial correlation. By averaging the data, the potential correlation between the averaged error term and the explanatory variables tend to vanish (see Barro and Sala-i-Martin 1991). We therefore decided, in order to overcome 
somehow these problems, to smooth out some of the individual time varying effects by taking five years averages for the period $1960-1985$. Thus, following this approach, Eq. (19) is estimated using five half decades for each of the 23 countries, making a total of 115 observations (23 times 5 ). In these regressions, $\hat{y}_{i t}$ and $\left(\hat{y}_{i t}-\hat{y}_{0}\right)$ are productivity and changes in productivity for country $i$ in the half-decade $t$ (i.e. productivity in the last year of $t$ and productivity growth during $t$ ) respectively. Similarly, the test of the variables are measured as the averages in the country $i$ between the start of the sample (1960) and half-decade $t$. For example, $s_{i t}$ is the average aggregate capital investment rate in country $i$ between 1960 and the end of period $t$, etc.

Estimation is done via non-linear least squares (NLS). In order to account for potential endogeneity of some regressors, in particular the net migration rate $m^{*}$ (given (12)), we also report the results of estimating the regression by instrumental variables, using non-linear-two-stage-least squares (NL2SLS). In this case, the dependent variable in (19) is the average income per capita growth with the averages of the relevant variables during the two previous half-decades acting as lagged instrumental variables. Apart from these lagged variables, we use a population density index (thousands of people per square meter) and its square as additional instruments for net migration. Thus, the number of instruments besides the initial condition, the constant terms and the country dummies, is 10 (two lags of $s_{k}, s_{h}$ and $m$, and the two density variables) making a total of seven overidentifying restrictions whose validity is tested by means of Sargan's (1958) test. Finally, note that by taking two lags of the variables as instruments, the sample size for the IV regression goes down from 115 to 92 observations (23 times 4).

\section{III.2 Data}

The data that we use mirror that used in the empirical analysis of MRW, except that our data base has been updated using the latest version of Summers and Heston (1991) "Real National Accounts for 138 countries". As previously mentioned, the availability of data on net migration has constrained the choice of countries to $23 \mathrm{OECD}$ nations with population greater than one million (except Luxembourg). This sample more or less corresponds to the third sample used in MRW, a feature that we will use for comparison purposes.

Labour productivity $\hat{y}$ for each country is measured as real GDP divided by the implicit adult population (working age population) in that year. The two investment rates are measured as follows. The rate $s_{k}$ corresponds to the share of total real investment (private and public) in real GDP. The rate $s_{h}$ has been constructed as in MRW, measuring approximately the percentage of the working population that is in secondary school. These two investment rates are then summed up to get the aggregate investment rate $s$. The population growth rate $n$ has been measured as the implicit adult (working-age) population growth rate, and the sum of $(g+\delta)$, again following MRW, has been assumed equal to 0.05 . Finally, the data on net migration has been elaborated by us using the sources described in the Data Appendix. Sample statistics are shown in Table 3.

\section{III.3 Results}

The estimation results are presented in Table 4 . Besides the parameters of interest $(\eta, \varepsilon$ and $\lambda)$, the $p$-values of the relevant tests are given. Test 1 refers to a test of 
Table 3. Sample statistics

\begin{tabular}{lllllllr}
\hline Variable & $\Delta y^{a v \mathbf{a}}$ & $y_{60}$ & $s_{k}$ & $s_{h}$ & $m^{b}$ & $m>0^{c}$ & $m<0^{\text {d }}$ \\
Mean & 2.85 & 6121 & 25.8 & 9.0 & 1.35 & 2.42 & -1.11 \\
Standard dev. & 0.95 & 2671 & 4.9 & 2.2 & 2.25 & 1.66 & 0.52 \\
\hline
\end{tabular}

Note:

${ }^{a} \Delta y^{a v}$ is the average growth rate of output per adult between 1960 and 1985.

${ }^{b}$ Average, unweighted, net migration rate per thousand; the correspondent weighted rate is $3.4 \%$.

c Average, unweighted, net migration rate per thousand for the 16 countries in which $m$ is positive.

${ }^{\mathrm{d}}$ Average, unweighted, net migration rate per thousand for the 7 countries in which $m$ is negative.

Table 4. Panel regressions for the convergence equation

\begin{tabular}{lcll}
\hline Estimated & \multicolumn{2}{l}{ Convergence equation (19) } & \\
\cline { 2 - 4 } parameters & $(1)$ & $(2)$ & $(3)$ \\
& Basic & Augmented & Augmented \\
& NLS & NLS & NLS2SLS \\
\hline$\eta=\alpha+\beta$ & $0.68(0.21)$ & $0.57(0.14)$ & $0.60(0.23)$ \\
$\varepsilon$ & & $0.26(0.11)$ & $0.34(0.13)$ \\
$\varepsilon_{h}^{1}$ (if $\left.\alpha=\beta\right)$ & & 0.52 & 0.68 \\
$\varepsilon_{h}^{2}$ (if $\left.\alpha=2 / 3 \beta\right)$ & & 0.65 & 0.85 \\
$\varepsilon_{h}^{3}($ if $\alpha=3 / 2 \beta)$ & $0.023(0.002)$ & 0.43 & 0.57 \\
$\lambda$ & 0.63 & $0.031(0.003)$ & $0.032(0.004)$ \\
$\bar{R}^{2}$ & 0.06 & 0.70 & 0.58 \\
$\sigma$ & 115 & 0.04 & 0.07 \\
NT & 0.26 & 115 & 92 \\
Test (1) $p$-value & 0.01 & 0.31 & 0.18 \\
Test $(2) p$-value & & 0.06 & 0.04 \\
Test (3) $p$-value & & & 0.16 \\
\hline
\end{tabular}

Note: The figures in parenthesis are the standard errors. $\bar{R}^{2}$ is the coefficient of multiple correlation (corrected by d.f.); $\hat{\sigma}$ is the standard error of residuals. NT is the number of observations.

Test (1) is a test for the restriction that the coefficient of $\ln \left(D+m^{*}\right)$ is equal with opposite sign to the cocfficients of $\ln (s)$ in Eq. (19).

Test (2) is an F-Test on the exclusion restrictions pertaining to the set of continent and grade of development dummies.

Test (3) is a Sargan's test of overidentifying restrictions.

the restriction entailed in (20), i.e. that the coefficient of $\ln (s)$ equals with opposite sign the coefficient of capital requirement $\ln \left(D+m^{*}\right)$. Test 2 is an F-test of the exclusion restrictions pertaining to a set of dummy variables, more or less corresponding to continent and degree of development. ${ }^{25}$ This set of countryspecific dummies turns out to be very significant and the estimated signs and sizes

25 These dummies have the following definitions:

DEU (dummy Europe): $\quad$ Austria, Belgium, Denmark, Finland, France, Germany, Italy, Luxembourg, Netherland, Norway, Sweden, United Kingdom, Switzerland;

DDE (dummy Development): Greece, Ireland, Spain, Portugal;

DPA (dummy Pacific): Australia, Japan, New Zealand;

DAM (dummy America): Canada, United States (excluded dummy). 
suggest the groupings. Their joint significance implies that the introduction of other explanatory variables (investment rates, etc.) is not enough to hold constant some features of the selected countries. Thus, in a sense, by introducing this set of dummies we may exert some control for permanent differences in tastes and technologies, which as mentioned in the previous section, could bias downwards the convergence parameter if they were not controlled for. Finally, Test 3 refers to Sargan's (1958) test of overidentifying restrictions in the regressions.

Table 4 presents the estimates of the parameters in (20) organised as follows. Column (1) reports the results without including the "pseudo migration" variable $\mu=\frac{\varepsilon m^{*}}{D+m^{*}}$ (basic regression); column (2) offers the estimates when such variable is included (augmented regression); column (3) reports the instrumental variables estimates of the augmented regression.

The basic regression offers results in agreement with the theory, i.e. growth rises with the differences between the total investment share and capital requirement ( $p$-value of the restriction $=0.26$ ), conditioning on the log of initial output per worker. Both the values of $\eta(=0.68)$ and of the speed of convergence $\lambda$ $(=0.023)$ are in line with the range of values estimated in the recent growth literature. Indeed, MRW report values for $\alpha$ and $\beta$, separately identifiable in their model, of about 0.33 each (therefore their $\eta$ would be about 0.66 ), while $\lambda$, in their preferred specification, is equal to 0.021 .

When the "pseudo migration" variable is introduced, as in column 2 , the coefficient of that variable turns out to be significant $(t$-ratio $=2.5)$, the $\bar{R}^{2}$ increases from 0.63 to 0.68 and the set of continent dummies becomes less significant. Moreover, the estimated joint share is smaller $(\eta=0.57)$ than in the basic regression, probably reflecting the fact that the non-augmented estimate is somehow upward biased. This because it is obtained excluding a variable whose coefficient in (19) is positive and whose correlation with the included regressor is likely to be positive. A similar comment, but in the opposite direction, could be made with respect to the increase in the estimated $\lambda$, from 0.023 in the basic regression to 0.031 in the augmented one. Indeed notice that once the net migration rate has been included in the capital requirement $\left(D+m^{*}\right)$, the exclusion of the "pseudo migration" variable in (19) should imply a downward bias in the estimate of $\lambda$, since the coefficient on the (log) of the initial condition in (19) is negative ( $\lambda$ being an increasing function of that coefficient) and the correlation between the "pseudo migration" variable and the initial conditions is likely to be positive.

When the NL2SLS estimates are considered, in column (3), the results are very much the same as in column (2), except that the estimated $\varepsilon$ tends to be higher, possibly reflecting the fact that migration is the variable most affected by simultaneity. Notice that the overidentifying restrictions (Test 3 ) are not rejected ( $p$-value $=0.16$ ).

As for the estimates of $\varepsilon$, these are always significant and range from 0.26 to 0.34 in the OLS and IV regressions. In order to afford comparisons with the values found in Sect. $I$, it is necessary to make some assumptions about the individual shares $\alpha$ and $\beta$, of which only the sum is identified in our model. Under these assumptions, $\varepsilon_{h}$ can be recovered from $\varepsilon=\varepsilon_{h} \frac{\alpha}{\alpha+\beta}$.

In order to cover the range of values typically found in the literature we distinguish three cases: 1) $\alpha=\beta$; 2) $\alpha=2 / 3 \beta$; and 3) $\alpha=3 / 2 \beta$. The corresponding 
suggest the groupings. Their joint significance implies that the introduction of other explanatory variables (investment rates, etc.) is not enough to hold constant some features of the selected countries. Thus, in a sense, by introducing this set of dummies we may exert some control for permanent differences in tastes and technologies, which as mentioned in the previous section, could bias downwards the convergence parameter if they were not controlled for. Finally, Test 3 refers to Sargan's (1958) test of overidentifying restrictions in the regressions.

Table 4 presents the estimates of the parameters in (20) organised as follows. Column (1) reports the results without including the "pseudo migration" variable $\mu=\frac{\varepsilon m^{*}}{D+m^{*}}$ (basic regression); column (2) offers the estimates when such variable is included (augmented regression); column (3) reports the instrumental variables estimates of the augmented regression.

The basic regression offers results in agreement with the theory, i.e. growth rises with the differences between the total investment share and capital requirement ( $p$-value of the restriction $=0.26$ ), conditioning on the log of initial output per worker. Both the values of $\eta(=0.68)$ and of the speed of convergence $\lambda$ $(=0.023)$ are in line with the range of values estimated in the recent growth literature. Indeed, MRW report values for $\alpha$ and $\beta$, separately identifiable in their model, of about 0.33 each (therefore their $\eta$ would be about 0.66 ), while $\lambda$, in their preferred specification, is equal to 0.021 .

When the "pseudo migration" variable is introduced, as in column 2 , the coefficient of that variable turns out to be significant $(t$-ratio $=2.5)$, the $\bar{R}^{2}$ increases from 0.63 to 0.68 and the set of continent dummies becomes less significant. Moreover, the estimated joint share is smaller $(\eta=0.57)$ than in the basic regression, probably reflecting the fact that the non-augmented estimate is somehow upward biased. This because it is obtained excluding a variable whose coefficient in (19) is positive and whose correlation with the included regressor is likely to be positive. A similar comment, but in the opposite direction, could be made with respect to the increase in the estimated $\lambda$, from 0.023 in the basic regression to 0.031 in the augmented one. Indeed notice that once the net migration rate has been included in the capital requirement $\left(D+m^{*}\right)$, the exclusion of the "pseudo migration" variable in (19) should imply a downward bias in the estimate of $\lambda$, since the coefficient on the $(\log )$ of the initial condition in (19) is negative ( $\lambda$ being an increasing function of that coefficient) and the correlation between the "pseudo migration" variable and the initial conditions is likely to be positive.

When the NL2SLS estimates are considered, in column (3), the results are very much the same as in column (2), except that the estimated $\varepsilon$ tends to be higher, possibly reflecting the fact that migration is the variable most affected by simultaneity. Notice that the overidentifying restrictions (Test 3 ) are not rejected ( $p$-value $=0.16$ ).

As for the estimates of $\varepsilon$, these are always significant and range from 0.26 to 0.34 in the OLS and IV regressions. In order to afford comparisons with the values found in Sect. I, it is necessary to make some assumptions about the individual shares $\alpha$ and $\beta$, of which only the sum is identified in our model. Under these assumptions, $\varepsilon_{h}$ can be recovered from $\varepsilon=\varepsilon_{h} \frac{\alpha}{\alpha+\beta}$.

In order to cover the range of values typically found in the literature we distinguish three cases: 1) $\alpha=\beta$; 2) $\alpha=2 / 3 \beta$; and 3) $\alpha=3 / 2 \beta$. The corresponding 
country that attracts the most skilled immigrants relative to natives, while Canada occupies an intermediate position and the United States do worse.

In comparing the education-based measures described in Sect. I with the estimated $\varepsilon_{h}$ in Table 5 , it should be kept in mind that the former are indicators of the human capital of immigrants without taking into accounts emigrants, while the latter are estimates of the relative human capital content of net migration. Thus, for the countries for which the net migration rate is negative, the estimated $\varepsilon_{h}^{1}$ has to be interpreted as the average human capital (relative to natives) of the net migration flow out of the country. For example, for Turkey and Portugal, the fairly low estimate of $\varepsilon_{h}^{1}$ seems to indicate that particularly low skilled workers leave the country. Relatively more skilled emigrants seem instead to leave Italy, another country in which the net migration rate is negative.

All in all, the characteristics of our estimated models appear to make sense. The estimates of $\eta(=\alpha+\beta)$ are in the range of values estimated in the literature, and they are significant in most cases. As for the convergence behaviour, when net migration is taken into account, the estimated speed of adjustment increases approximately from 0.02 to 0.03 with an implied $35 \%$ reduction of the number of years to cover half the distance to the steady state (from 34 to 23 years). This suggests that even with the relatively low net migration rate of our sample, the adjustment is somewhat faster. Thereforc, in environments in which labour mobility were higher (regions within a country) the convergence rate could be considerably accclerated by larger migration flows, provided that the human capital content of these flows were comparable to the one estimated here.

As a conclusion to this section, given the fairly satisfactory performance of our empirical model, we proceed in attempting an evaluation of the overall output and growth effect of immigration using the estimated parameters. On the basis of the point estimates described in Table 4, and assuming $D=0.05, \varphi=0.01$ and $m^{*}=0.0034$ (the population-weighted average in our sample), a one per thousand increase of net migration reduces output per capita in the steady state by $1.6 \%$. The same increase of net migration reduces instead the growth rate of output per capita by 0.04 percentage points. ${ }^{26}$ As for the effects of a change in the immigrants versus natives human capital ratio, starting from $\varepsilon_{h}^{\prime}=0.68$ (the value implied by the restricted estimate in Table 5), a 0.1 increase of this parameter increases output per capita in steady state by $0.41 \%$ and the current growth rate by 0.017 percentage points. ${ }^{27}$

These numbers indicate, on the one hand, the possibility of some positive, but weak, effects of a higher immigrants' human capital for a given size of the migra-

26 These effects are given by the following expressions:

$$
\frac{\partial \ln \left(\hat{y}^{*}\right)}{\partial Z}=\frac{-\eta(1-\varepsilon)}{\lambda} \text { and } \frac{\partial \gamma_{y}}{\partial Z}=-\eta(1-\varepsilon),
$$

where $\hat{y}^{*}$ is output per capita in steady state, $\gamma_{y}$ is the growth rate of output per capita, and $Z$ is exogenous net migration.

27 The effects of a higher immigrants' human capital are given by:

$$
\frac{\partial \ln \left(\hat{y}^{*}\right)}{\partial \varepsilon}=\frac{\alpha m^{*}}{\lambda} \text { and } \frac{\partial \gamma_{y}}{\partial \varepsilon}=\frac{\alpha}{\alpha+\beta} m^{*} .
$$


tion inflow. They also indicate, on the other hand, the possibility of negative effects of a larger migration inflow, for a given level of the immigrants' human capital. These latter negative effects imply that the level of immigrants' human capital is too low to offset the negative output and growth effects of immigration. Nevertheless, it may still be large enough to substantially differentiate the effects of immigration from the effects of a comparable natural population increase. In fact, on the basis of the parameter values described above, if the native population grows by one per thousand, the current output per capita decreases by $4.0 \%{ }_{0}{ }^{28}$ Therefore, because of its human capital content, a migration inflow has less than half the negative impact of a comparable natural population increase.

\section{Conclusions}

In this paper we have analysed the effects of migration in an Solow growth model augmented by migration and human capital. The basic message that we draw from the above analysis can be summarised as follows. Although immigration represents a source of population growth, it cannot be assumed to share, quantitatively, the same negative output and growth effects, in per capita terms, of a natural increase in native population. The reason is the stock of human capital that immigrants bring with themselves when they enter the country. Yet, in the presence of other reproducible factors of which immigrants are not endowed, the human capital content of a migration inflow would have to be extremely high in order to neutralise the negative output and growth effects of immigration in per capita terms.

Evidence based on education data suggests that the human capital content of international migration flows is indeed fairly high, making immigrants look, on average, almost as skilled as natives. The econometric results show that this is enough to halve the negative impact of immigration with respect to a comparable natural increase of the host country population. It is also enough to cause fairly limited effects on growth, but it leaves room for sizeable long run effects on the steady state output level, which is reduced, and on the speed of adjustment, which is increased.

It should be noticed that these conclusions are reached in a framework in which immigrants contribute to the host country human capital accumulation only with the skills that they have accumulated in the country of origin. However, after arrival in the host country, immigrants may also accumulate human capital differently than natives thereby influencing, during the assimilation process, the host country accumulation of reproducible factors. Leaving for future research an explicit analysis of the sign and size of these effects, here we conjecture that they may make the overall impact of immigration less dramatic than usually thought.

We hope that our quantitative effort, although based on a simple theoretical model and on limited data, may represent a useful benchmark for future more exhaustive attempt at identifying and measuring the growth effects of migration flows.

28 The impact of natural population growth on current output per capita is given by:

$$
\frac{\partial \ln (\hat{y})}{\partial n}=\frac{\partial \ln \left(\hat{y}^{*}\right)}{\partial Z}\left(\frac{1}{\eta(1-\varepsilon)}\right)=-\frac{1}{\lambda} .
$$


The data on the migration inflows used in Sect. I are drawn from a United Nations source (see Zlotnick 1991). This source provides migration inflows, classified by countries of origin, for nine receiving countries: Australia, Canada, US, Belgium, the Federal Republic of Germany, the Netherlands, Sweden, Switzerland and the United Kingdom. For the criteria used to identify immigrants in these countries see Zlotnick (1991).

The schooling data used in Sect. I to measure the natives' and immigrants' human capital originate from three different sources: Secondary school enrollment data, provided by the World Bank; Educational attainment data provided by Barro and Lee (1992) and Educational attainment data provided by Kyriacou (1991). See these references for a more detailed description of these data.

The OECD net migration flows used in the econometric analysis of Sect. III originate from three sources: Eurostat, Zlotnick (1991) and United Nations (1989 Annual Statistical Yearbook). To select between these data sources, a ranking order has been established: priority has been given to the Eurostat source, then the Zlotnick source and finally the United Nations source, according to the availability of data. Since net migration data were not available for the United States, migration inflows have been used instead.

The other data used in the econometric analysis are from the Summers and Heston data base (1991), which covers the 1960-1988 period for 138 countries. We used the data for 23 OECD countries, listed in Table 5 in the text.

The implicit working-age population has been computed by weighting the total Real GDP by the Real GDP per equivalent adult, both measures being taken at 1985 international prices.

The rate of human capital accumulation $\left(s_{h}\right)$, due to difficulties in gathering yearly data for the age-population distribution, has been constructed using the school variable computed by Mankiw, Romer and Weil (1992), augmented by the total population in each year, weighted by the average population over the 1965-1980 period for each reference country.

The rate of physical capital accumulation $\left(s_{k}\right)$ is measured as the Investment share of GDP, in percentage terms, at 1985 international prices.

\section{References}

Barro RJ (1991) Economic growth in a cross section of countries. Qu J Econ 106:407-443

Barro RJ, Lee J-W (1992) International comparison of educational attainment. Harvard University Press, Cambridge

Barro R, Sala-i-Martin X (1991) Convergence across states and regions. Brooking Papers on Economic Activity $1: 107-157$

Barro R, Mankiw D, Sala-i-Martin X (1992) Capital mobility in neoclassical models of growth. Mimeo NBER

Baumol WJ (1986) Productivity growth, convergence and welfare: what the long run data show. Am Econ Rev 76:1072-1085

Benjamin D, Baker M (1992) The performance of immigrants in the Canadian labor market. Mimeo, University of Toronto

Blitz R (1977) A benefit-cost analysis of foreign workers in West Germany, 1957-1973. Kyklos $30: 479-502$

Borjas GJ (1985) Assimilation, changes in cohort quality and the earning of immigrants. J Labor Econ 3:463-489 
Borjas GJ (1987) Self selection and the earnings of immigrants. Am Econ Rev 77:531-553

Borjas GJ (1990) Friends or strangers: the impact of immigrants on the US economy. Basic Books, New York

Burda M, Wyplosz C (1991 a) Human capital, investment and migration in an integrated Europe. CEPR Discussion Paper

Burda M, Wyplosz C (1991 b) Labour mobility and German integration: some vignettes. CEPR Discussion Paper

Cartiglia F (1992) Essays on human capital and the theory of international trade. Columbia University Kimes, New York

Chiswick BA (1978) The effect of Americanization on the earnings of foreign born men. J Polit Econ 86:897-921

Chiswick BA (1979) The economic progress of immigrants: some apparently universal patterns. In: Fellner W (ed) Contemporary economic problems. American Enterprise Institute, Washington, DC, pp 357-399

Chiswick BA (1980) Immigrants earnings patterns by sex, race and ethnic groupings. Monthly Labor Rev $168-192$

Cohen D (1992) Tests of the 'convergence hypothesis': a critical note. CEPREMAP

Dolado J, Goria A, Ichino A (1993) Immigration, human capital and growth in the host country. Evidence from pooled country data. FEEM Working paper 67.93

Dowrick S, Nguyen D (1989) OECD comparative growth 1950-1985: catch-up and convergence. Am Econ Rev 79:1010-1030

Gini C (1940) Europa und America. Zwei Welten. Weltwirtsch Arch 52:1-37

Greenwood MJ, McDowell JM (1986) The factor market consequences of US immigration. J Econ Liter 24:1738-1772

Ichino A (1993) The economic impact of immigration on the host country. In: Luciani G (ed) Migration policies in Europe and the United States. Kluwer, Dordrecht, pp 145-162

Kyriacou GA (1991) Level and growth effect of human capital. A cross-country study of the convergence hypothesis. New York University

Lucas RE (1988) On the mechanics of economic development. J Monet Econ 22:3-42

Mankiw R, Romer D, Weil D (1992) A contribution to the empirics of economic growth. Q J Econ 107:407-437

Rebelo (1991) Long-run political analysis and long-run growth. J Polit Econ 99:500-521

Sala-i-Martin X (1990) Lecture notes on economic growth. NBER Working Papers No 3563 and No 3564, Cambridge

Sargan JD (1958) The estimation of economic relationships using instrumental variables. Econometrica $26: 393-415$

Simon JL (1989) The economic consequences of immigration. Basic Blackwell-Cato Institute Publishers, Oxford

Solow RM (1956) A contribution to the theory of economic growth. Q J Econ 71:65-94

Stark O (1991) The migration of labor. Blackwell, Oxford

Summers R, Heston A (1991) The penn world table (Mark 5): an expanded set of international comparisons, $1950-1988$. Q J Econ 106:327-368

Zlotnick H (1991) Trends in south to north migration: the perspective from the north. 1OM

Zlotnick H, Hovy B (1990) Trends in European migration: what the data reveal. United Nations, New York 